\title{
EXPERIMENTAL AND HARMONIC MODAL ANALYSIS OF COMPOSITE SPUR GEAR USING ANSYS ACP
}

\author{
KAREEM ABDULGHAFOUR ABDULLA ${ }^{1}$, SAFEENYASEENEZDEEN ${ }^{2} \&$ ALFONS AMS $^{3}$ \\ ${ }^{1,2}$ Department of Mechanical \& Mechatronics Engineering, College of Engineering, Salahaddin University-Erbil,Iraq \\ ${ }^{3}$ Faculity of Mechanical Engineering, Department of Mechanics \& Fluid Dynamic, Technical University Freiberg, Freiberg, \\ Germany
}

\begin{abstract}
This paper presents the effect of composite materials that included limited damping material on vibrating structures modal. The current study selected two symmetrical laminates having [(0/90 $\left.)_{66}\right]_{s}$ carbon-epoxyE502, and glassepoxyCG202. Measurements are carried out on structure of the spur gears by using hammer test. Comparisons of the results of the experimental and finite-element study found that the damping ratio and the natural frequencies of structures are well thoroughly investigated. Also experimentally determined were natural frequency, frequency response, and damping ratio of the structures. The gear was modelled in CAD SOLIDWORKS software in this paper while in ANSYS ACP Workbench 17.2 modal and response harmonic analysis were performed for various boundary conditions. It can be concluded that the composite materials are actually perfect for the noise and vibration reduction. The results show that the composite material can have a spectacular effect on the weight of the drive system without considering strength.
\end{abstract}

KEYWORDS: Composite Material, Spur Gear, Hammer Test, Frequency Response, Damping Ratio, ANSYS ACP

Received: Jun 08, 2020; Accepted: Jun 28, 2020; Published: Oct 03, 2020; Paper Id.: IJMPERDJUN20201466

\section{INTRODUCTION}

Gears are the most important components in modern mechanical engineering world. The use of gearshas more common in all the industries. The advantages of spur gear are simplicity in design and can bemanufactured easily, economically and less maintenance. At present scenario composite gears plays an important role in wide space of research especially in gear motors, gear pumps, electromechanical actuators and drive shafts for car etc., Composite gears have better mechanical characteristics like wear resistance, corrosion resistance, lubricant free, noiseless, high strength to weight ratio[1].Metal matrix composites (MMCs) are an essential product used in engineering materials. This product has wide applications in automotive, aerospace, and other uses[2].Robert F. Handschuh [3] investigated hybrid gear ( composite material-metallic) at NASA Glenn Research Center. Although the design was not optimized for weight, the composite gears were found to be 20 percent lighter that the all-steel gears. Fee vibration modes and vibration/noise test were also conduct to compare the vibration and damping characteristic of the Hybrid Gear to all-steel gears. The initial results indicate that this type of hybrid design may have a dramatic effect on drive system weight sacrificing strength.Omer Yavus Bozkurt [4] was measured dynamic characteristic of Basalt Epoxy composite laminates by using an experimental set-up according to ASTM E756, fibre orientation of basalt/epoxy, and the laminates having higher fibre 5orientation angle had higher damping ratios, also the increase in angle of fibre orientation from $0^{\circ}$ to $45^{\circ}$ resulted in decrease in natural frequency. Bagul 
A.D. [5] was compared an experimental with finite element analysis by Ansys software results to determine the natural vibration modes of the Gearbox casting component in order to prevent resonance. It concluded that the FEA results for the gearbox casting component for four speed G65-4 speed with full remote shifting shows close agreement with the experimental modal test data. YiqiangJiang[6] was studied about new type of cycloidal drives with a rubber ring was proposed and produced using modal analysis. whose shaw's hardness is $80 \mathrm{o}$ has better modal characteristics than traditional cycloidal drives by more effectively avoiding resonance region. JongBoonOoi [7] used modal analysis on three different gear trains of the portal axle unit was studied using FEM simulation under free-stress state and pre-stressed state. There was a big difference between the natural frequency of the gear trains compared to the operating frequency of the portal axle unit in which it is a normal case. However, modal analysis must be performed as a safety precaution in portal axle design.

\section{EXPERIMENTAL WORK AND PROCEDURES}

\subsection{Materials and Methods}

For this analysis, two new commercial materials, carbon-epoxyE502 and glass-epoxyGC202, and detailed properties of symmetrical laminates shown in Table1. are selected. The products were purchased from the carbonscout company[8] and picked for comparison the aluminium spur gear. The basic parameters of the aluminium are set to density $2608 \mathrm{Kg} / \mathrm{m}^{3}$, elastic modulus $71000 \mathrm{MPa}$, poisson's ratio 0.33, tensile strength $280 \mathrm{MPa}$.

Table 1: Mechanical properties of laminates , [8]

\begin{tabular}{|c|c|c|c|c|}
\hline & Property & Unit & $\begin{array}{l}\text { Carbon-Epoxy } \\
\text { E502 Prepeg }\end{array}$ & $\begin{array}{c}\text { Glass-Epoxy GC202 } \\
\text { Prepeg }\end{array}$ \\
\hline 1 & Young's Modulus X direction (E1) & $\mathrm{MPa}$ & 130000 & 24000 \\
\hline 2 & Young's Modulus Y direction (E2) & $\mathrm{MPa}$ & 115000 & 24000 \\
\hline 3 & Poisson's Ratio XY & - & 0.27 & 0.30 \\
\hline 4 & Poisson's Ratio YZ & - & 0.40 & 0.35 \\
\hline 5 & Tensile $\mathrm{X}$ direction & $\mathrm{MPa}$ & 2000 & 430 \\
\hline 6 & Shear Modulus XY & $\mathrm{MPa}$ & 125000 & 55 \\
\hline 7 & Compressive $\mathrm{X}$ direction & $\mathrm{MPa}$ & -1200 & -520 \\
\hline 8 & Density & $\mathrm{Kg} / \mathrm{m}^{3}$ & 736.5 & 1700 \\
\hline 9 & Thickness & $\mathrm{mm}$ & 0.30303 & 0.30303 \\
\hline $\begin{array}{l}1 \\
0\end{array}$ & Number of plies & - & 66 & 66 \\
\hline \multicolumn{3}{|c|}{ Commercial name of laminate } & $\begin{array}{c}\text { SIGRAPREG }^{\circledR} \mathrm{C} \\
\text { U600- 0/NF- } \\
\text { E502/35\% }\end{array}$ & $\begin{array}{c}\text { Tafel EP GC202 EN } \\
60893-3-2\end{array}$ \\
\hline
\end{tabular}

\subsection{Composite gear design and manufacturing:}

Table 2: summarizes the basic design employed for this study. The gears were made using laminated fabrics with dimensions of $300 \mathrm{~mm} \times 300 \mathrm{~mm}$ and thickness of $20 \mathrm{~mm}$. In this study a total of three gears were fabricated and used.

\begin{tabular}{|c|c|}
\hline Number of teeth..................................17 & 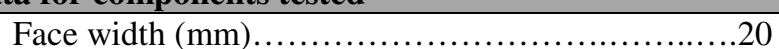 \\
\hline 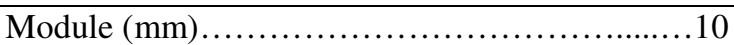 & 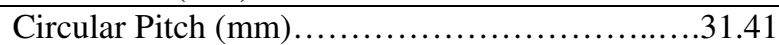 \\
\hline $\begin{array}{l}\text { Pressure Angle (degree) } \ldots \ldots \ldots \ldots \ldots \ldots \ldots \ldots \ldots \ldots \ldots \ldots \ldots \ldots \ldots \ldots \ldots \ldots \\
\end{array}$ & Fillet Radius $(\mathrm{mm}) \ldots \ldots$ \\
\hline 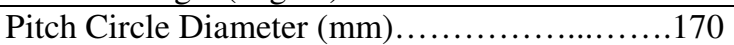 & Whole depth $(\mathrm{mm}) \ldots .$. \\
\hline 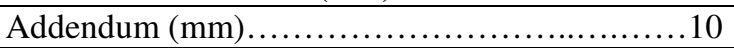 & Weight Carbon-Epoxy E502 gear $(\mathrm{Kg}) \ldots \ldots \ldots \ldots . . .601$ \\
\hline Base Circle Diameter $(\mathrm{mm}) \ldots \ldots \ldots \ldots \ldots \ldots \ldots \ldots \ldots .75$ & Weight Glass-Epoxy GC202 gear $(\mathrm{Kg}) \ldots \ldots \ldots \ldots .817$ \\
\hline Outside Circle Diameter $(\mathrm{mm}) \ldots \ldots \ldots \ldots$ & Weight Aluminium gear $(\mathrm{Kg}) \ldots \ldots \ldots \ldots$ \\
\hline Diametral Pitch $(\mathrm{mm}) \ldots \ldots \ldots \ldots \ldots \ldots \ldots \ldots \ldots \ldots \ldots \ldots$ & \\
\hline
\end{tabular}




\subsection{Instrumentation and measuring equipment :}

Fast Fourier Transform ( FFT) with data acquisition device made of Scadas Front End is the research equipment used for the experiments.

- The structure was excited using impact hammer, model (Dytran Make 5800B3) at all predefined locations as indicated in Fig. 1.(a,b)

- Piezoelectric accelerometer, model (PCB T30356B1 \& 30356B1 G), with $100 \mathrm{mV} / \mathrm{g}$ sensitivity, at an identified driving point transfer function (DPTF) location. The type of experimental modal analysis is known as the Frequency Response Function (FRF).

- Connecting cables for impact hammer and accelerometer,

- Data acquisition system sound and vibration data acquisition, to receive and analyse signals received from the impact hammer and accelerometer.

- Personal Computer, to the essence of all frequency response functions (FRF's) was resolved to extract natural frequencies and mode shapes. Fig.2. shows the experimental modal analysis set up for gears.

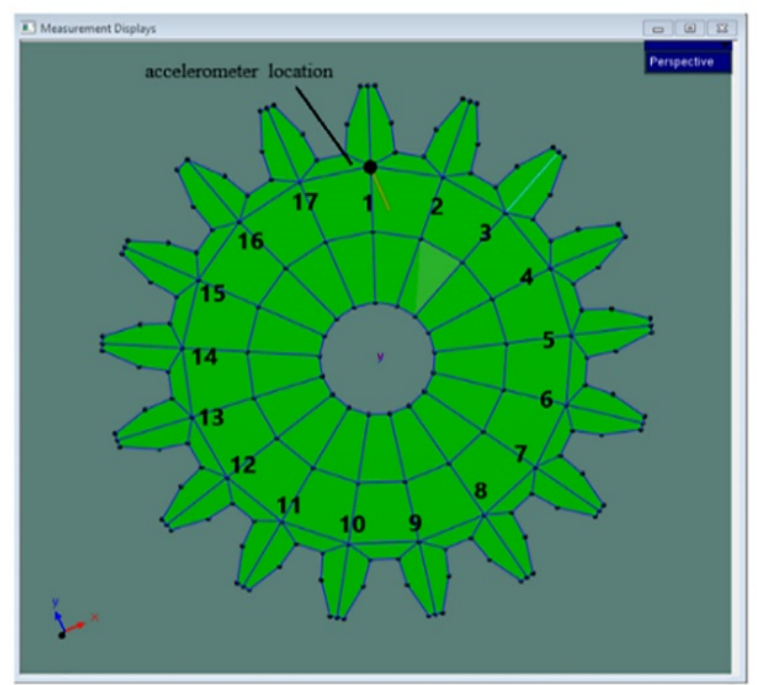

Figure 1: a) Axial location from point 1 to 17 of hammer test, and point 1 location of accelerometer 


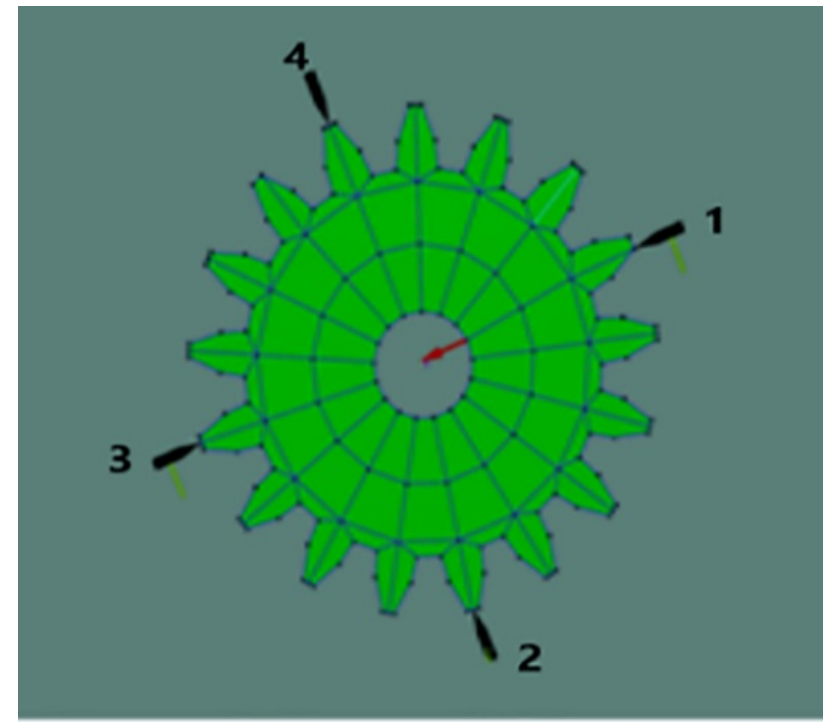

Figure 1: b) Radial location of 4 points

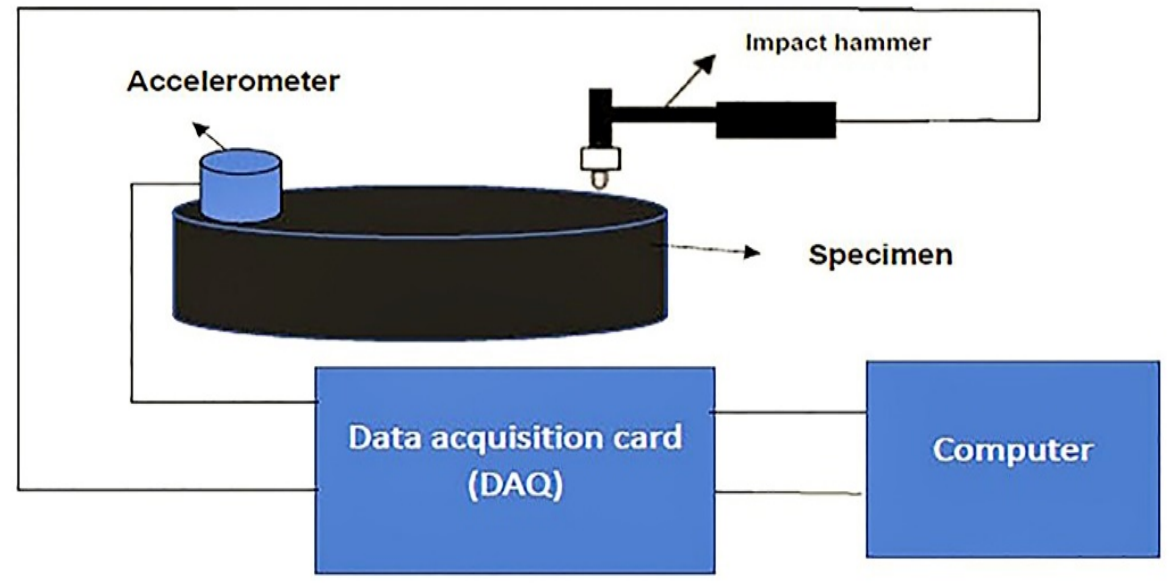

Figure 2: A measurement set-up with hammer excitation

\subsection{Experimental Modal Analysis Procedure}

The experimental research set-up consists of impact hammer and accelerometer. The specimen was positioned on the $39,64 \mathrm{~kg} / \mathrm{m}^{3}$ density soft foam with $370 \times 300 \times 15 \mathrm{~mm}$ dimensions in order to allow free vibration (see Fig.3).The gear was suspended by an elastic band, with this soft support at the 12 o'clock for radial test as shown in Fig.4. The case was attached to point 1 of a single accelerometer on the axial direction structure as shown in Fig.1.a. Both the two composite gears and the aluminium gear were subjected to the axial direction and radial direction of the series of impacts. The location selected 4 points at the three, six, nine and twelve o'clock for the radial impacts, as shown in Fig.1.b. And selected 17 points for the axial impact location as shown in Fig.1.a.The three gears were tested through the experimental modal analysis with free - free boundary conditions (see Fig.3\&Fig.4). 


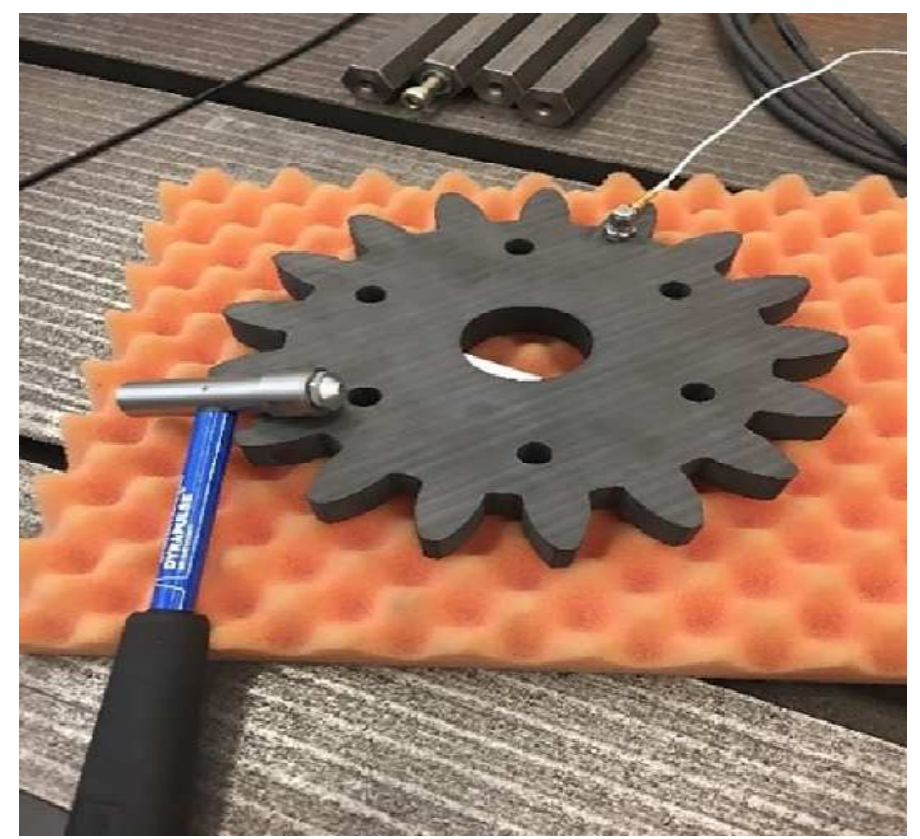

Figure 3: Axial test of gear of specimen carbon E502, accelerometer localization

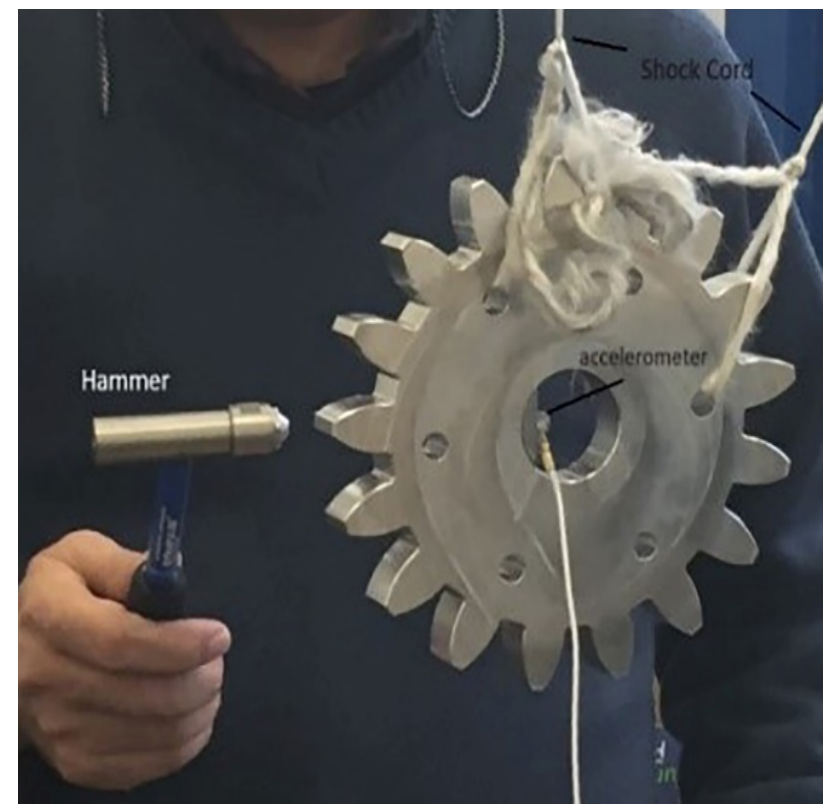

Figure 4: Radial test of free-free condition for spur gear of specimen Aluminium

\subsubsection{Measurement of Damping}

For first natural frequency of the experiment, half-power band-width procedure was used to calculate damping responses. Damping is expressed in various ways in mechanical systems and the most common types are $\boldsymbol{Q}$ and here $\boldsymbol{Q}$ is amplification or quality factor, and $\zeta$ the viscous damping ratio or critical damping fraction. The half power bandwidth method is also used to estimate damping ratio from frequency domain on a decibel scale this corresponds to a $3 \mathrm{db}$ drop from the peak.For this reason, the damping measurement technique is also called as $3 \mathrm{db}$ method. The $3 \mathrm{db}$ point are also called as "Half power points" when they represent on the transfer magnitude curve. By looking at three dB down from the peak level, one can determine the associated damping as shown in Fig.5 and according to Equation (1) [9]. And Fig.6 illustratesthe procedure to calculate the damping ratio as used in the test gear of aluminium, which damping is the energy 
dissipation properties of a material or system under cyclic stress[9][10].

$$
2 \zeta=\frac{1}{Q}=\eta=\tan \phi=\frac{f_{2}-f_{1}}{f_{0}}
$$

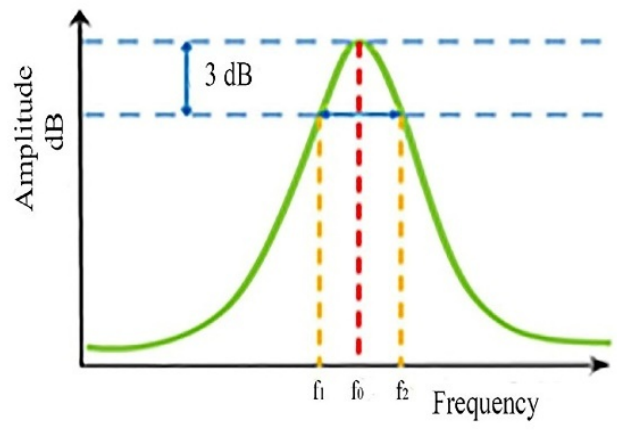

Figure 5: The $3 \mathrm{~dB}$ method diagram for calculating the damping factor $Q$.

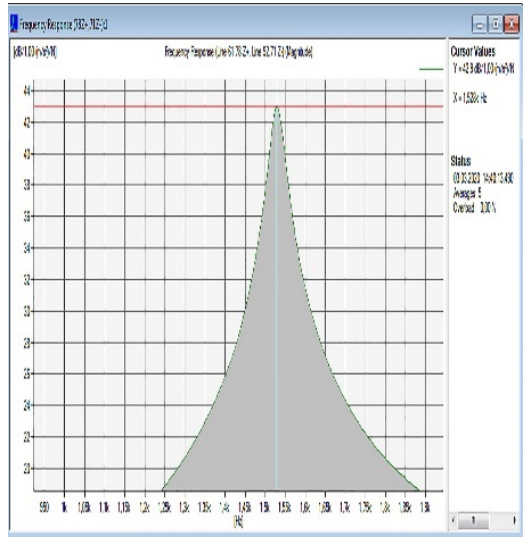

$f_{0}=1528 \mathrm{~Hz}$

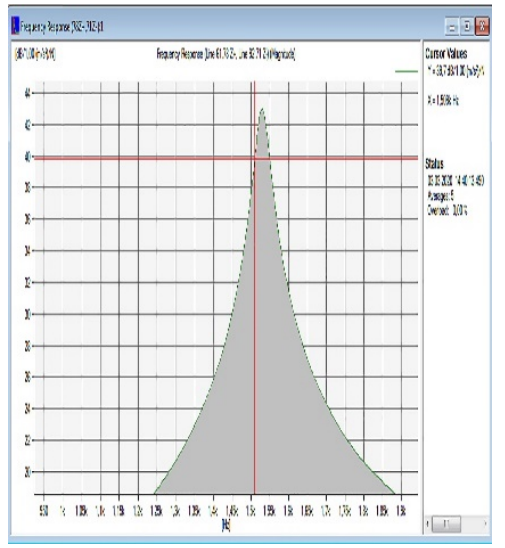

$f_{1}=1509 \mathrm{~Hz}$

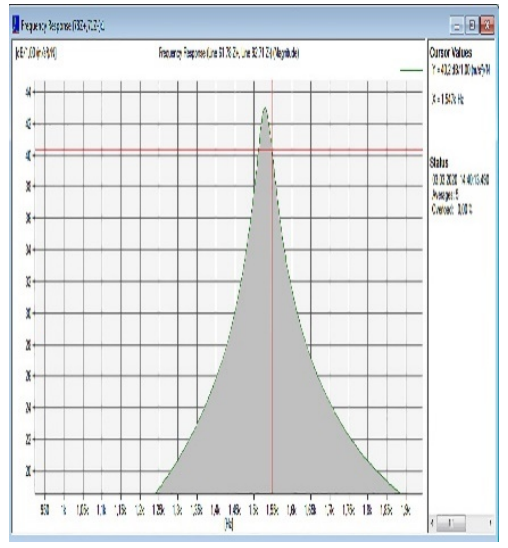

$f_{2}=1547 \mathrm{~Hz}$

Fig. 6 - Measurement of the frequencies as used in the test gear of Aluminium

$\zeta=\frac{f_{2}-f_{1}}{2 f_{0}}, \zeta=\frac{(1547-1509)}{2 *(1528)}, \zeta=0,00625$

Fig.7.and Fig.8 illustratesthe method of calculating logarithmic decrement as used in the test gear of aluminium, Where $\mathbf{A}_{\mathbf{n}}$ is the displacement at the $\mathrm{n}^{\text {th }}$ peak, and $\mathrm{n}$ is number of cycles.

$$
\boldsymbol{\delta}=\frac{1}{n} \frac{\ln A_{1}}{\ln A_{n}}
$$

$f_{0}=2762.5 \mathrm{~Hz}$

\section{from Fig.8}

at $\mathbf{t}_{1}=10.94 \mathrm{~ms}$ then $\mathrm{A}_{1}=16817$

at $\mathbf{t}_{\mathbf{5 0}}=29.06 \mathrm{~ms}$ then $\quad \mathbf{5 0}=7531$ 
$\mathrm{n}=50$

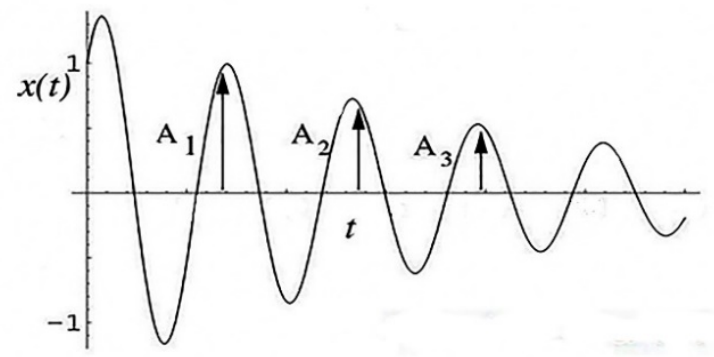

Figure 7: The method of calculating logarithmic decrement
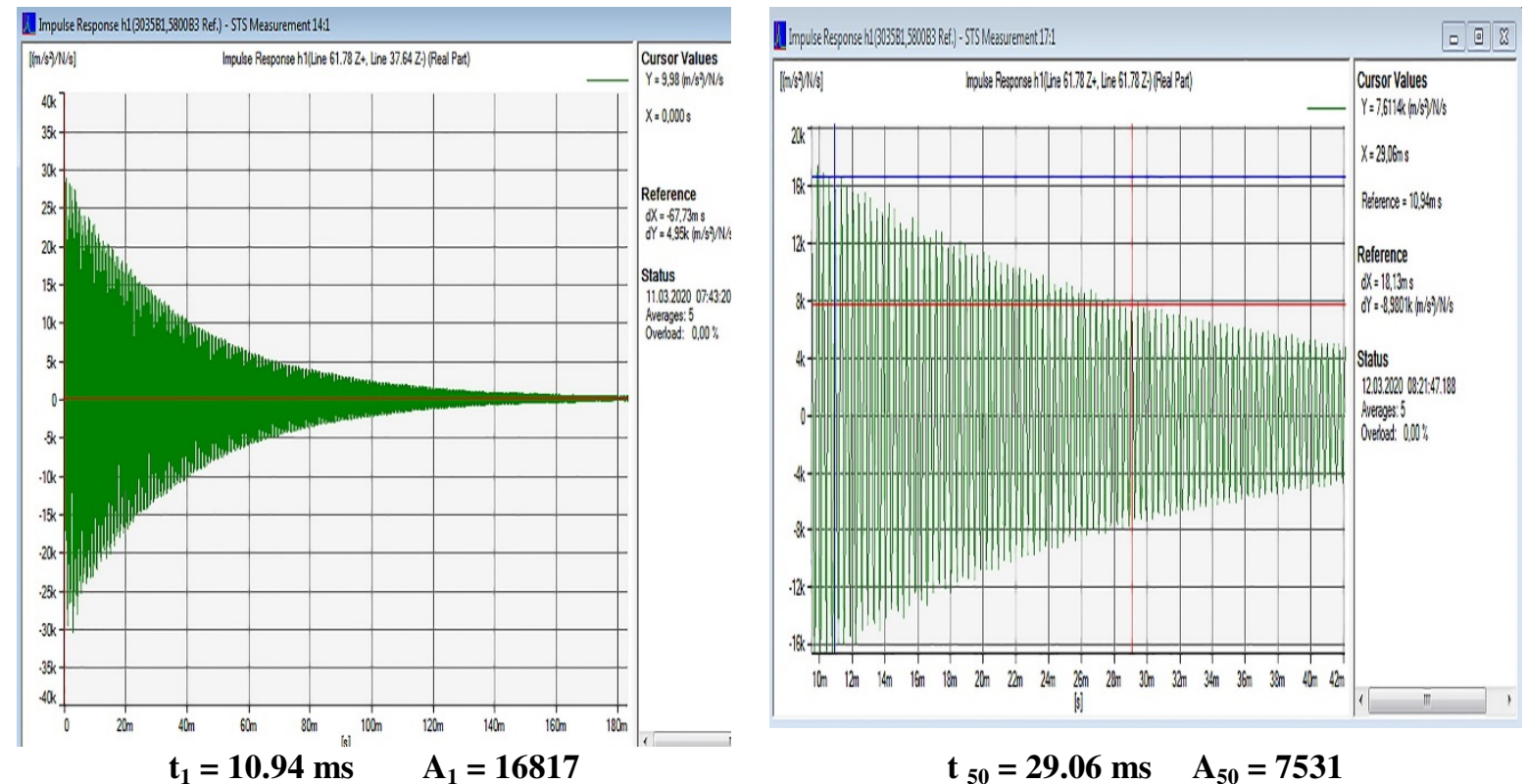

Figure 8 - Procedure to calculate the logarithmic decrement as used in the test gear of Aluminium

$\boldsymbol{\delta}=\frac{1}{n} \frac{\ln A_{1}}{\ln A_{n}}, \boldsymbol{\delta}=\frac{1}{50} \frac{\ln 16817}{\ln 7531}, \boldsymbol{\delta}=\mathbf{0 . 0 2 1 8}$

Also can calculate damping ratio $\zeta=\frac{\delta}{2 \pi}=\frac{\mathbf{0 . 0 2 1 8}}{2 \pi}=\mathbf{0 . 0 0 3 5}$

\section{FINITE ELEMENT ANALYSIS (ANSYS ACP)}

\subsection{Laminate and Lamina}

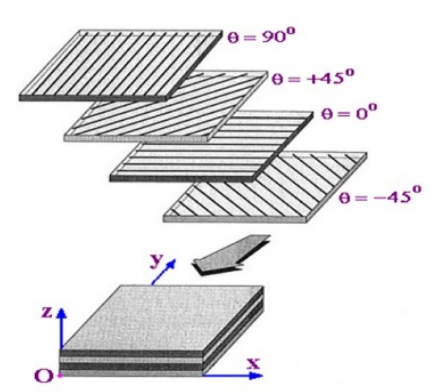

Figure 9: show the number, thickness and orientation of laminate 
Laminate is a layer with a number with lamina arranged in a proper sequence with a defined thickness of each lamina. The layers are layered and then cemented together in such a direction that the angle of the fibre orientation (everywhere) varies with each layer as seen in Fig.9. We selected two specimens of laminates, to explain the technique. First case, carbon-epoxyE502 and second case, glass-epoxyGC202 with 66 layers having a [(0/90) $\left.)_{\mathbf{6 6}}\right]_{\mathbf{S}}$ stacking sequence. For further detail, see Table 1.,[8], each layer thickness of the laminates is $0.30303 \mathrm{~mm}$ and the overall composite thickness is $20 \mathrm{~mm}$; in a cross ply laminate, fibre orientation angles in alternative layers are $\mathbf{0}^{\mathbf{0}} / \mathbf{9 0}^{\mathbf{0}} / \mathbf{0}^{\mathbf{0}} / \mathbf{9 0} \mathbf{0}$.

\subsection{Modelling in ANSYS ACP}

To predict the spur gear's dynamic behaviour, a 3D model must be created first using a CAD software with the geometries of the gear at which it is attached (see Table 2.). In this project, the SOILDWORKS software is used to create the model, and the geometry is saved in a portable format, in STEP or (IGES format.). ANSYS Composite PrepPost is a specialized tool for sample preparation and evaluation of composite structures results. Program ANSYS Composite PrepPost is fully integrated in ANSYS Workbench platform [11].

- $\quad 3 D$ Modelling of the components geometry using SOLIDWORKS Software;

- $\quad$ Exporting the assembly from SOLIDWORKS Software in IGES (or STEP) format and importing it in ANSYS simulation program (ANSYS 17.2);

- $\quad$ Start ANSYS workbench and drag ACP (Pre) to project schematic;

- $\quad$ Add the materials (carbon-epoxyE502) and (glass-epoxyGC202) to engineering data;

- $\quad$ Select required material from engineering data;

- Enter the desired profile (gear) in the geometry and design and select the edit surface to adjust the thickness to 0 mm so that Modal can be opened in the next step;

- $\quad$ Open Model cell, assign material at $0.30303 \mathrm{~mm}$ thickness and complete mesh

- Open setup, select and create Fabrics under Material Data (carbon-epoxyE502) to prepare the stacks;

- $\quad$ Create Ply with different angles as required;

- Use oriented elements to create a Ply Group and enter angles 0 and 90, repeat the process for 66 layers;

- $\quad$ Add new rosette to model and define a rosette type as parallel;

- Create new oriented element set using rosette and elements set as required;

- Update the model and convert to a solid model;

- $\quad$ Drag and drop static structural workbench to project schematic and connect setup cell from ACP (Pre) to model cell in modal select option "transfer solid data";

- $\quad$ Open the model cell in Modal and Check the geometry; and running the study;

- Analysis of the results summary of composite material properties at specific locations which are presented in Table 3. [12] 
Table 3: Properties of materials as used in the test gears obtained by ANSYS ACP 17.2

\begin{tabular}{|c|l|c|c|c|}
\hline \multicolumn{2}{|c|}{ Property } & Unit & $\begin{array}{c}\text { Carbon-Epoxy } \\
\text { E502 Composite }\end{array}$ & $\begin{array}{c}\text { Glass-Epoxy GC202 } \\
\text { Composite }\end{array}$ \\
\hline 1 & Young's Modulus X direction ( E1) & $\mathrm{MPa}$ & 123494.55 & 24000 \\
\hline 2 & Young's Modulus Y direction ( E2) & $\mathrm{MPa}$ & 122499 & 24000 \\
\hline 3 & Poisson's Ratio XY & - & 0.27 & 0.30 \\
\hline 4 & Poisson's Ratio YZ & - & 0.40 & 0.35 \\
\hline 5 & Tensile X direction & $\mathrm{MPa}$ & 2000 & 430 \\
\hline 6 & Shear Modulus XY & $\mathrm{MPa}$ & 124883.2 & 5000 \\
\hline 7 & Compressive X direction & $\mathrm{MPa}$ & -1200 & -520 \\
\hline 8 & Density & $\mathrm{Kg} / \mathrm{m}^{3}$ & 1400 & 1900 \\
\hline
\end{tabular}

\section{RESULTS AND DISCUSSIONS}

\subsection{Model Property Estimates}

A series of experiments using a modal impact on the standard AISI 9310 composite spur gear and aluminium spur gear specimen were conducted to identify natural frequencies, to calculate modal damping ratio by equation (1) and logarithmic decrement by equation (2), and the experimentally determined mean and standard deviation ofthe natural frequencyas shown in Table 4. The carbon-epoxyE502 gear and glass-epoxyGC202 gear show better damping properties than the gear in aluminium.The carbon-epoxyE502 damping ratio for glass-epoxyGC202 was determined to be 0.0121 and 0.0099 , the low value 0.00252 of aluminium when the position of impact was chosen at axial point. In modal analysis the decay constant, $\sigma$ is often used since $-\sigma$ indicates the real part of the pole location of transfer functions in the Laplace plane. On decay curves the decay constant, $\sigma$ corresponds to the number of $-8.7 \mathrm{dBs}$ the curve decays per second [13]. At another hand, the measurement of the composite materials damping factor 67.56 to 69.53 was less than the 235.69 aluminium.

Table 4: Specimen Modal Property Estimates

\begin{tabular}{|c|c|c|c|c|c|c|c|}
\hline \multirow{2}{*}{\multicolumn{2}{|c|}{$\begin{array}{l}\text { Impact position } \\
\text { Gear specimen }\end{array}$}} & \multicolumn{3}{|c|}{ Axial } & \multicolumn{3}{|c|}{ Radial } \\
\hline & & & Glass & & Carbon & Glass & Aluminium \\
\hline \multirow{2}{*}{$\begin{array}{l}\text { Damping Ratio } \\
(\zeta)(3 \mathrm{~dB})\end{array}$} & Mean & 00121 & 00090 & 000252 & 00138 & 00102 & 000252 \\
\hline & $\begin{array}{l}\text { Standard } \\
\text { deviation }\end{array}$ & 0.00336 & 0.0032 & 0.00081 & 0.00013 & 0.0014 & 0.00976 \\
\hline \multirow{2}{*}{$\begin{array}{l}\text { Damping Ratio } \\
(\zeta)(-8.7 \mathrm{~dB})\end{array}$} & Mean & 0.0038 & 0.0081 & 0.00160 & 0.0139 & 0.0118 & 0.00268 \\
\hline & $\begin{array}{l}\text { Standard } \\
\text { deviation }\end{array}$ & 0.00234 & 0.0026 & 0.00046 & 0.00012 & 0.0023 & 0.00106 \\
\hline \multirow[t]{2}{*}{ Log decrement $(\boldsymbol{\delta})$} & Mean & 0.0059 & 0.0072 & 0.00120 & 0.0957 & 0.0019 & 0.00120 \\
\hline & $\begin{array}{l}\text { Standard } \\
\text { deviation }\end{array}$ & 0.00015 & 0.0016 & 0.00038 & 0.0015 & 0.0009 & 0.00037 \\
\hline \multirow[t]{2}{*}{ Damping Factor $(\boldsymbol{Q})$} & Mean & 67.56 & 69.53 & 235.69 & 36.23 & 49.81 & 226.81 \\
\hline & $\begin{array}{l}\text { Standard } \\
\text { deviation }\end{array}$ & 19.57 & 26.19 & 85.77 & 4.40 & 7.65 & 94.67 \\
\hline \multicolumn{2}{|c|}{ Natural frequency $(\mathrm{Hz})$} & $6131 \pm 47$ & $\begin{array}{c}6397 \pm \\
43\end{array}$ & $9896 \pm 65$ & \multicolumn{3}{|c|}{$\mathrm{n}=17$ data samples } \\
\hline
\end{tabular}

\subsection{Frequency Response Analysis}

The frequency response of carbon-epoxyE502 and glass-epoxyGC202 has been found to be much smaller than that of aluminium. It means that the toughness of the carbon-epoxyE502 and glass-epoxyGC202 modulus in combination is very low compared to aluminium, as seen in Fig.10. 


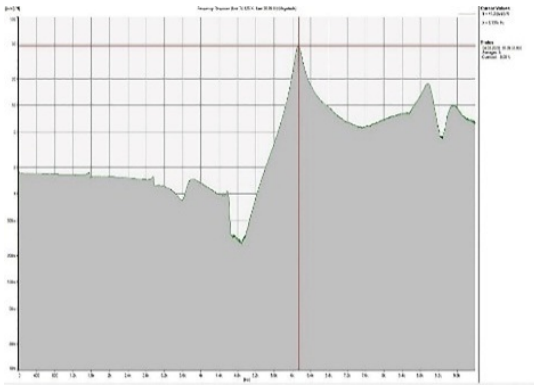

a) Carbon-EpoxyE502 $f_{0}=6131 \mathrm{~Hz}$

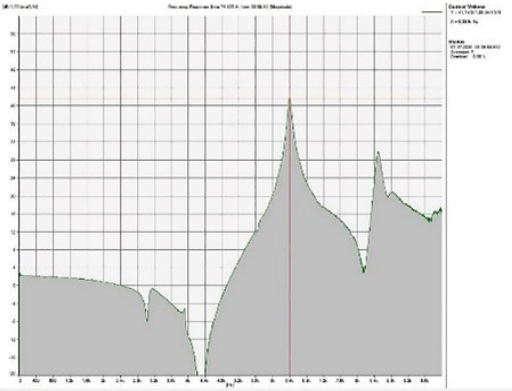

b) Glass-Epoxy GC202 $f_{0}=6397 \mathrm{~Hz}$

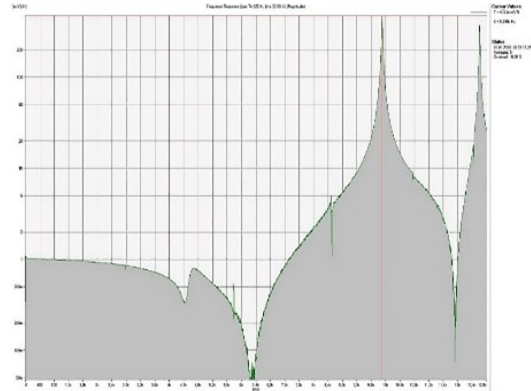

c) Aluminium $f_{0}=9896 \mathrm{~Hz}$

Figure 10: Frequency response of typical impact tests for gears used

\subsection{Natural Frequency and Modal Shape Analysis}

For the 17-tooth composite spur gear, modal analysis was also performed to validate the natural frequencies found in the experiment and to determine the related mode shapes compared to the aluminium spur gear. The finite element mesh is a solid mesh of 59928 elements with a total of 68207 nodes for the carbon-epoxyE502 and 56562 elements and a total of 69546 nodes for the glass-epoxyGC202. The characteristic element size is around $2 \mathrm{~mm}$. The first six modes found in the study are static translations of the body and rigid rotations. So the frequencies associated with these modes are shown in Table 5 starting at mode 7 to 12 .

Table 5: Finite element frequency (ANSYS) and expremintal frequency measurement (EFM) of spur gears

\begin{tabular}{|c|c|c|c|c|c|c|}
\hline \multirow{2}{*}{ Mode } & \multicolumn{2}{|c|}{ Carbon-Epoxy E502 } & \multicolumn{2}{c|}{ Glass-Epoxy GC202 } & \multicolumn{2}{c|}{ Aluminum } \\
\cline { 2 - 7 } & ANSYS (Hz) & $\begin{array}{c}\text { EFM } \\
(\mathbf{H z})\end{array}$ & $\begin{array}{c}\text { ANSYS } \\
(\mathbf{H z})\end{array}$ & $\begin{array}{c}\text { EFM } \\
(\mathbf{H z})\end{array}$ & $\begin{array}{c}\text { ANSYS } \\
(\mathbf{H z})\end{array}$ & $\begin{array}{c}\text { EFM } \\
(\mathbf{H z})\end{array}$ \\
\hline 7 & 4674 & 4572 & 1553 & 1719 & 2995.8 & - \\
\hline 8 & 6189 & 6125 & 1995 & 2053 & 2996.2 & 4873 \\
\hline 9 & 8426 & 6422 & 3284.1 & 3269 & 5175.8 & 5753 \\
\hline 10 & 9795 & 6919 & 3568 & - & 6116.8 & 7632 \\
\hline 11 & 9810 & 7816 & 3570.8 & 3922 & 6117.6 & - \\
\hline 12 & 12763 & 8472 & 5131.5 & 5641 & 8924 & 8492 \\
\hline
\end{tabular}

The research done comes from ANSYS Workbench's modal analysis. The characteristics of the vibrations are the natural frequencies and mode shapes. It set the maximum number of modes to be identified to 12 . The combined mode of twisting and bending relates to mode 7 to 8 and 10 of (carbon-epoxyE502, glass-epoxyGC202 and aluminium) and the mode of the flying wing relates to mode 9 (see Fig.11).The mode shapes of the simulated natural frequencies are shown from Fig. 11 to Fig. 13. The deformation and type of mode of the gears for each mode can be seen in each of the figures. The maximum deformation for composite material occurred in mode 10, and for aluminium was noted in mode 12. 


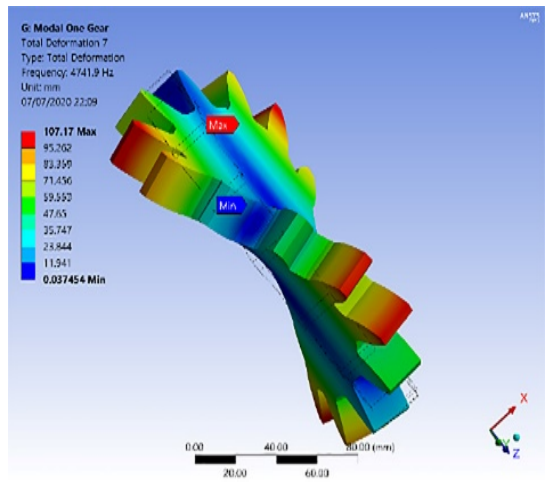

Mode 7 bending \& Twisting (deformation=106 mm)

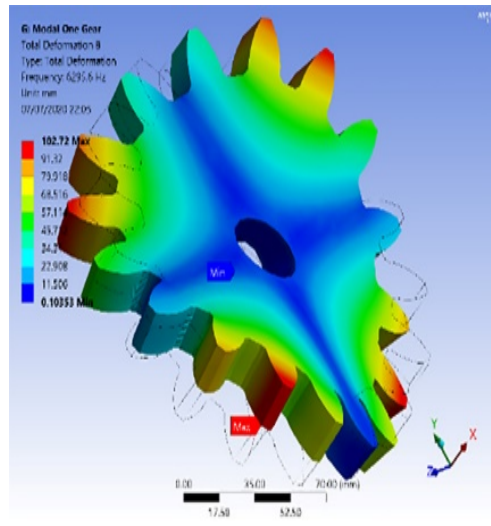

Mode 8 bending \& Twisting (deformation $=102 \mathrm{~mm}$ )

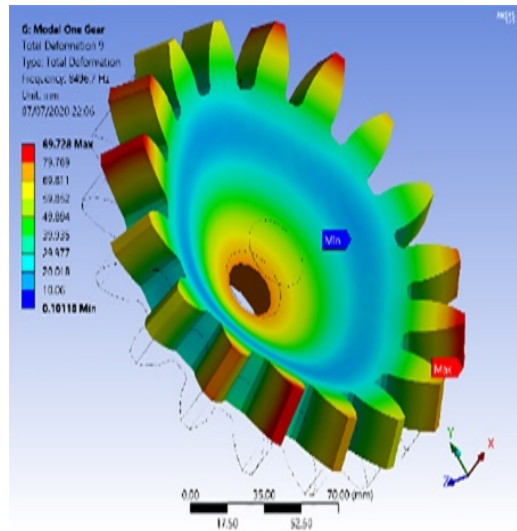

Mode 9 flying wing shape (deformation $=88 \mathrm{~mm}$ )

Figure 11: Carbon-Epoxy E502 shape mode from 7 to 9

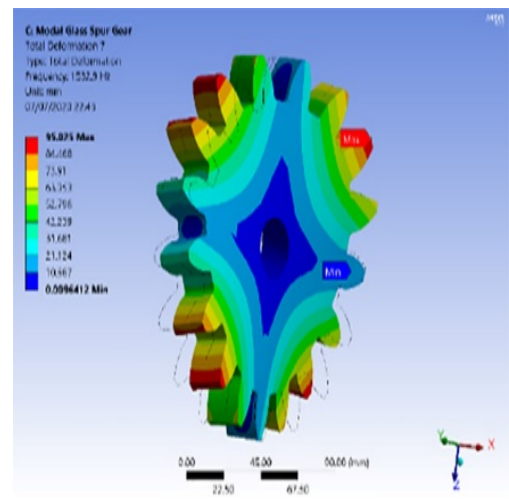

Mode 7 bending \& Twisting (deformation= $96 \mathrm{~mm}$ )

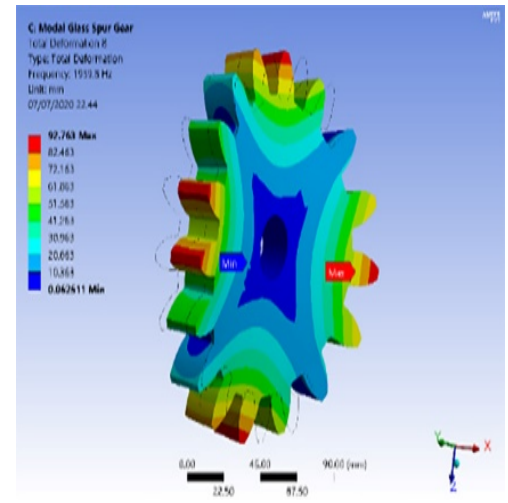

Mode 7 bending \& Twisting (deformation= $94 \mathrm{~mm}$ )

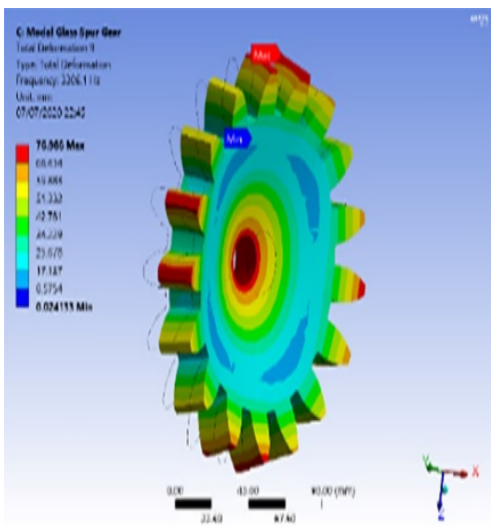

Mode 9 flying wing shape (deformation $=78 \mathrm{~mm}$ )

Figure 12: Glass-Epoxy GC202 shape mode from 7 to 9

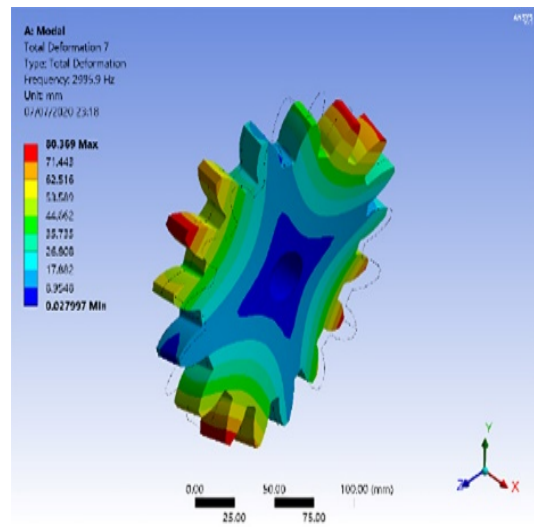

Mode 7 bending \& Twisting (deformation $=96 \mathrm{~mm}$ )

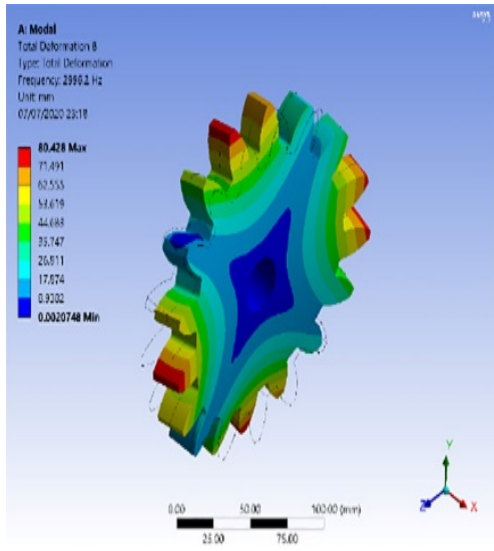

Mode 7 bending \& Twisting (deformation $=96 \mathrm{~mm}$ )

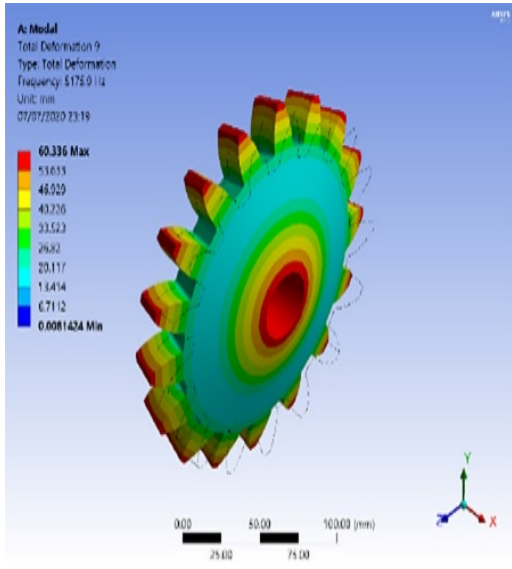

Mode 9 flying wing shape $($ deformation $=67 \mathrm{~mm})$

Figure 13: Aluminum shape mode from 7 to 9

\subsection{The Harmonic Response Analysis}

This research attempts to determine the natural frequency response and the harmonic frequency response of the gear to avoid resonance for three gear types[14][15]. The analysis was carried out for 0-18000 Hz frequency range. This range was obtained after Natural Frequency Calculation. Different boundary conditions were added. Damping is important in the 
study of the frequency response, and has been applied to the model.A damping ratio was added to model, exactly a 0.0121 for carbon-epoxy E502, 0.0099 for glass-epoxyGC202 and 0.00252 for aluminium of material damping. Harmonic analysis is then conducted to calculate the structure's response at several frequencies to obtain a graph of amplitude versus frequency. The results of the harmonic response analysis shown in Fig.14.(a) with no addition of the damping ratio, the frequency response was $7272 \mathrm{~Hz}$. When the damping ratio (0.0121) is applied to the system, the result show that the frequency response $(13140 \mathrm{~Hz})$ for specimen carbon-epoxyE502 is shifting away from the system resonant frequency, as the frequency response is considered to be $6131 \mathrm{~Hz}$ as mentioned in Fig.10. And Fig.14.(b) When the damping ratio was applied (0.0099), the frequency response for the specimen glass-epoxyGC202 was more shifted from frequency $2850 \mathrm{~Hz}$ to $3130 \mathrm{~Hz}$ as the frequency response is considered to be $6397 \mathrm{~Hz}$. While the aluminium specimen was moved from $8456 \mathrm{~Hz}$ to $3108 \mathrm{~Hz}$ when the damping ratio (0.00252) was applied, as the frequency response is assumed to be $9896 \mathrm{~Hz}$. (See Fig. $14(c))$.

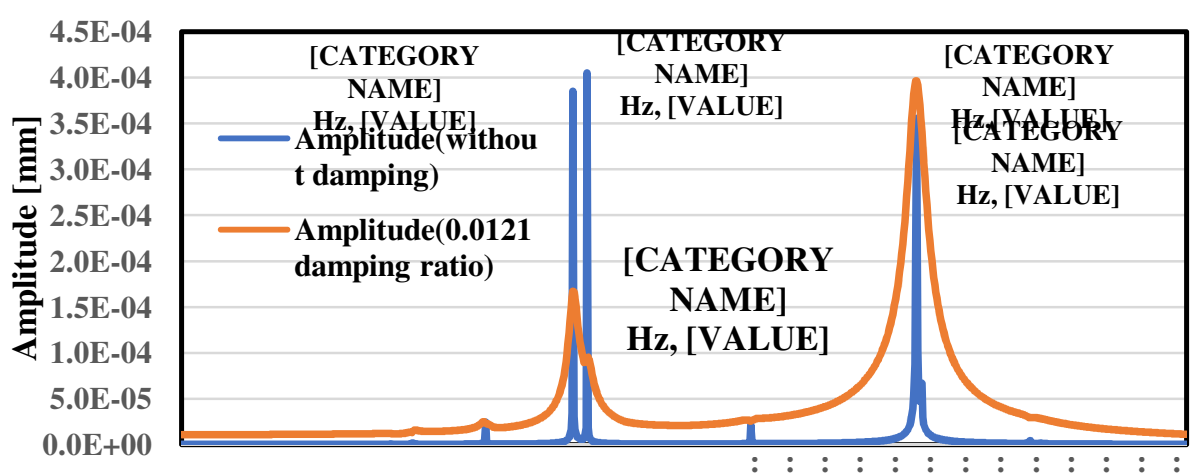

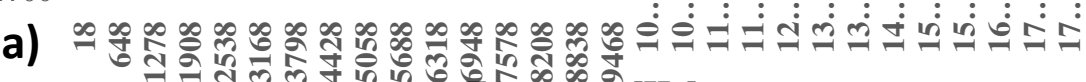
Frequency $[\mathrm{Hz}]$

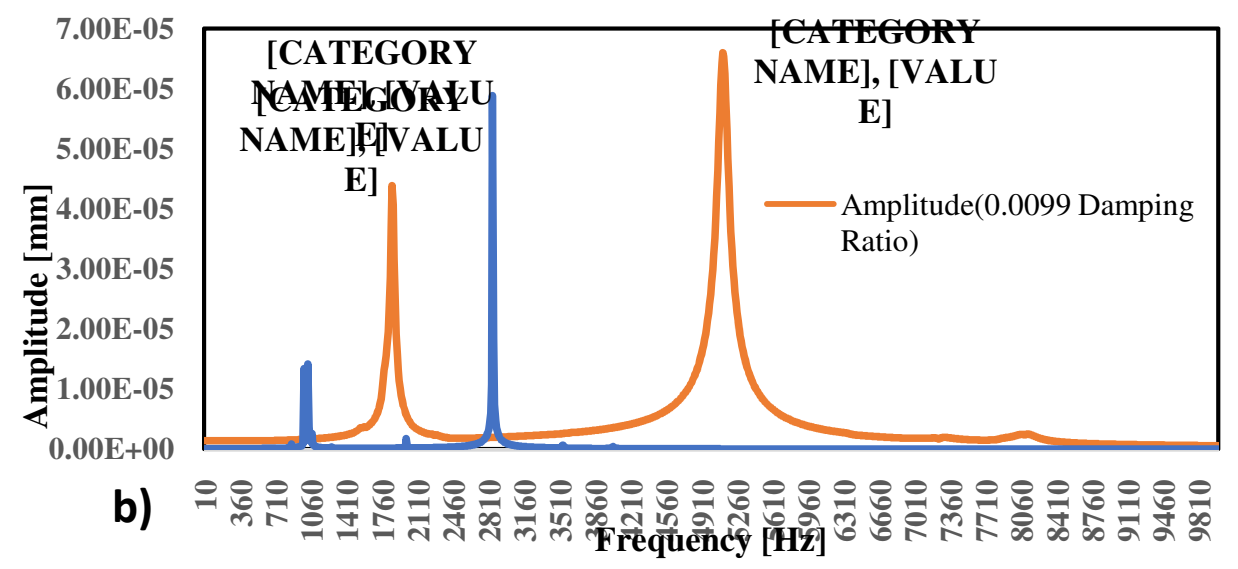

$1.8 \mathrm{E}-05$

$1.6 \mathrm{E}-05$

1.4E-05

$1.2 \mathrm{E}-05$

1.0E-05

8.0E-06

6.0E-06

4.0E-06

2.0E-06

$0.0 \mathrm{E}+00$

1.00E-03

8.00E-04

$6.00 \mathrm{E}-04$

4.00E-04

2.00E-04

$0.00 \mathrm{E}+00$ 


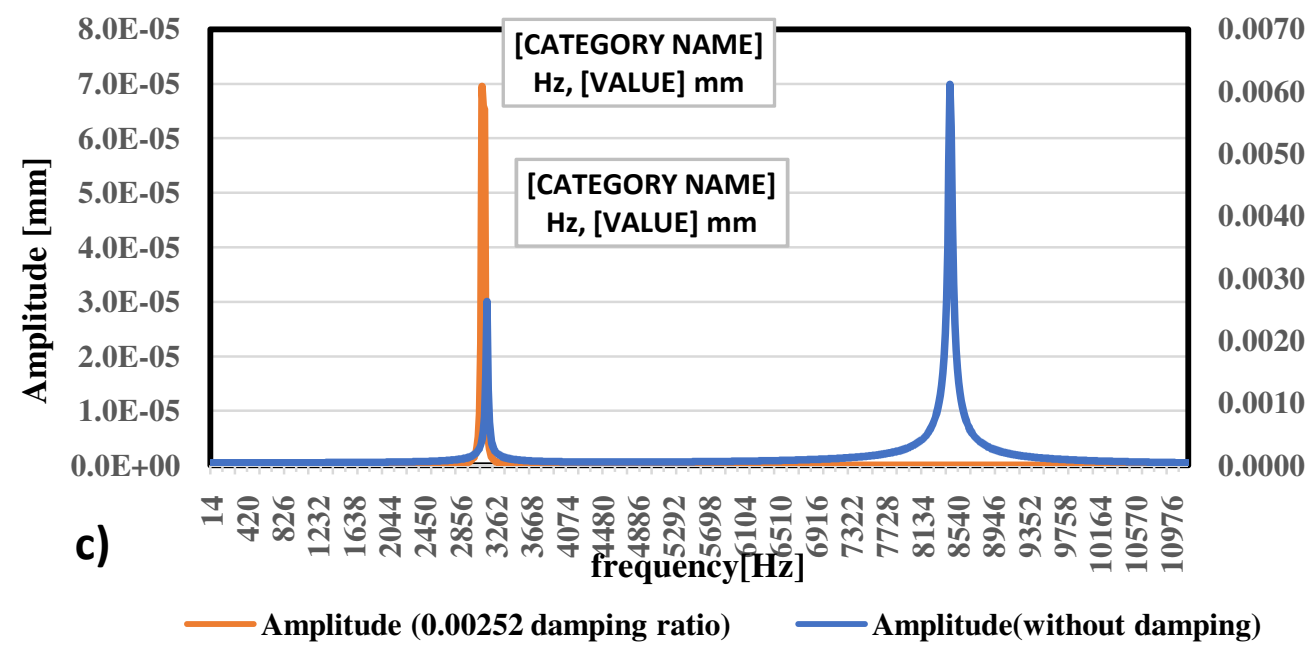

Figure 14: Harmonic analysis .a) Specimen carbon-epoxy E502, in direction-X,b) Specimen glass-epoxy GC202, in direction-X, c) Specimen aluminium, in direction $-Z$.

\subsection{Comparison of Experimental Frequency Measurement and Finite Element Frequency Prediction}

A comparison was performed between the finite element analysis ANSYS and the experimental results to approach validating the concept of finite element analysis. Fig.15. Glass-epoxyGC202 and aluminium results show good agreement between model predictions and the results of the experiments. At the other hand, for the specimen carbon-epoxyE502, the percentage error is 0.43 , some of the carbon-epoxyE502 parameters are not supposed to be similar to the real. The percentage error of both glass-epoxyGC202 and aluminium, it looks close to experimental.

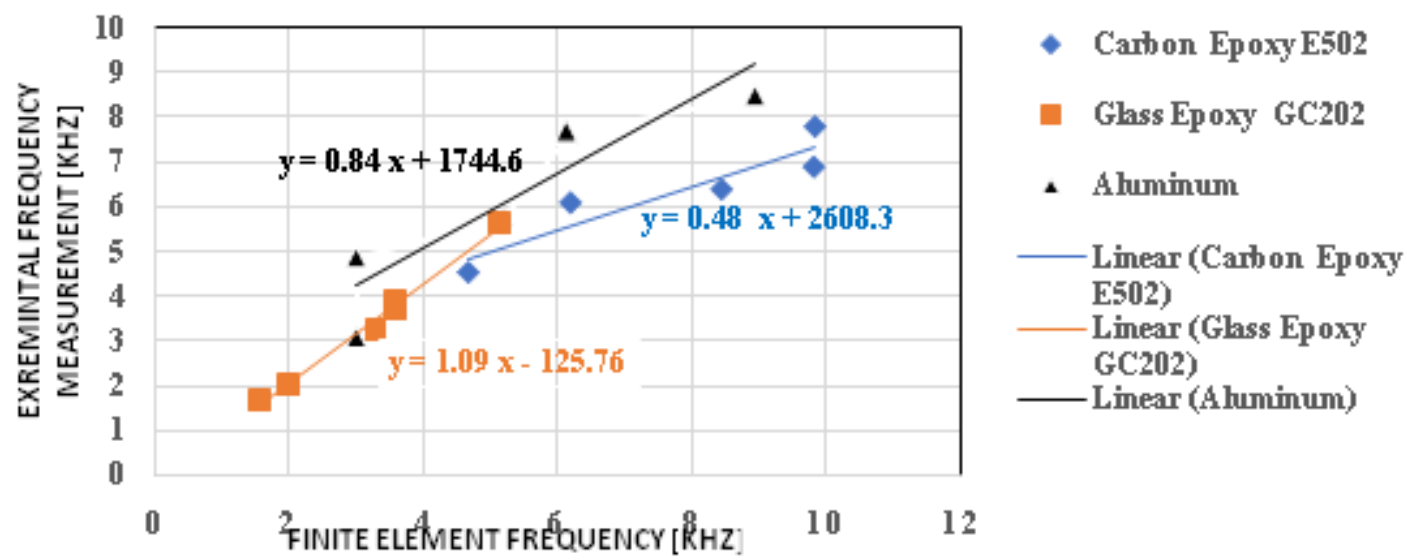

Figure 15: Comparison of experimental frequency measurement and finite element frequency prediction

The relationship between the slope $a$ of a nonvertical line and the line's angle of inclination $(\theta)[16]$ :

$\mathrm{y}=a \mathrm{x}+b$

Inclination angle $\boldsymbol{\theta}=\tan ^{-1}(a)$

The optimum angle of inclination is equal $45^{\circ}$ when $a=1\left(\tan 45^{\circ}=1\right)$

from Figure 15,y $=0.48 x+2608.3$ line equation of specimen Carbon-Epoxy E502 
$\mathrm{y}=1.09 \mathrm{x}-125.76$ line equation of specimen Glass-Epoxy GC202

$y=0.84 x+1744.6$ line equation of specimen aluminium

Table 6: Calculation percentage error between finite element frequency prediction and experimental frequency measurement

\begin{tabular}{|c|l|c|c|c|c|}
\hline No. & \multicolumn{1}{|c|}{ Spur gear specimen } & $\begin{array}{c}\text { Slope of line ( } \\
\boldsymbol{a})\end{array}$ & $\begin{array}{c}\text { Inclination } \\
\text { angle } \mathbf{( \boldsymbol { \theta } )}\end{array}$ & $\begin{array}{c}\text { Difference } \\
(\text { Absolute value) }\end{array}$ & Error \% \\
\hline 1 & Carbon-EpoxyE502 & 0.48 & $25.64^{\circ}$ & $45-25.64=19.36^{\circ}$ & $19.36 / 45=0.430$ \\
\hline 2 & Glass-EpoxyGC202 & 1.09 & $47.46^{\circ}$ & $47.46-45=2.46^{\circ}$ & $2.46 / 45=0.054$ \\
\hline 3 & Aluminium & 0.84 & $40.00^{\circ}$ & $45-40.00=5.00^{\circ}$ & $5.00 / 45=0.111$ \\
\hline
\end{tabular}

\section{CONCLUSIONS}

A series of experiments using a modal impact was conducted on the composite spur gear and aluminium spur gear specimen to identify natural frequencies. The frequency response of carbon-epoxyE502 (6131 Hz) and glass-epoxyGC202 $(6397 \mathrm{~Hz})$ has been found to be much lower than that of aluminium $(9896 \mathrm{~Hz})$. The carbon-epoxyE502 damping ratio for glass-epoxyGC202 was found to be 0.0121 and 0.0099 , the low value 0.00252 of aluminium when the place of impact was selected at axial location. The estimate of the composite materials damping factor 67.56 to 69.53 was lower than the 235.69 aluminium. It can be concluded that the frequency response of composite materials is not close to resonance when no damping is added, but aluminium needed an added damping ratio to move it away to a safe place, and therefore composite materials are preferred because the amount of damping ratio is large. Therefore, it concludes that composite materials are good for reducing noise and vibration. The results using ANSYS ACP are close to experimental results, with the exception of carbon-epoxy E502, the percentage of error (0.43). This indicates that very few of the information transmitted is incorrect and therefore it is possible to rely on the results extracted from the ANSYS ACP. The weight of the composite materials is much less than 25 to 45 per cent in aluminium. Preferred use of composite material on the design structures has enabled more stability of rotational movements and reduced the moment of inertia.

\begin{tabular}{|l|l|}
\hline NOMENCLATURE \\
\hline$\square$ Damping Ratio & $\square$ loss factor \\
\hline$\square$ Logarithmic decrement & $\square$ Damping angle or quality factor \\
\hline$\square$ Natural frequency & $\square$ Phase angle between stress and strain \\
\hline
\end{tabular}

\section{ACKNOWLEDGMENTS}

This study was mainly supported by the Department of Mechanical \& Mechatronics Engineering, College of Engineering, Salahaddin University-Erbil, Ministry of Higher Education and Scientific Research, Kurdistan Regional Government(KRG), Iraq.

\section{REFERENCES}

1. Paper :S. Rajeshkumar, R. Manoharan.Design and analysis of composite spur gearsusing finite element method. IOP Conference Series: Materials Science and Engineering. 263 (2017) 062048.

2. Fakhir Aziz RasulRozhbiany, ShawnimRashied Jalal. Reinforcement and processing on the machinability and mechanical properties of aluminum matrix composites. Journal of Material Research and Technology, 2019;8(5):4766-4777.

3. Robert F. Handschuh, Gary D. Roberts, Ryan R. Sinnamon,David B. Stringer, Brian D. Dykas, Lee W. Kohlman. Hybrid Gear Preliminary Results-Application of Composites to Dynamic Mechanical Components. LERCIP Summer Intern at NASA Glenn Research Center, NASA/TM-2012-217630. 
4. Paper: Omer Yavus Bozkurt, MehemtBulut, OzkanOzbek. Effect of Fiber Orientation on Damping Characteristic of Basalt Epoxy Composite Laminates.In: Proceeding of the World Congress on Civil,Structure and Environmental Engineering (CSEE'16),ICSENM 115,March-2016.

5. Bagul A.D., Barijibhe R. B,Patil A. V. . Vibration Analysis Gearbox Casting Component using FEA Tool ANSYS and FFT Analyzer. International Journal of Engineering Research \& Technology (IJERT) ,2014;3(2).

6. YiqiangJiang, Li Hou, Yunixa You, Jingyu Zhang. Structure Design and Modal Analysis for a New Type of Cycloidal Drives . International Journal of Simulation -- Systems, Science \&Technology . 2016;17 (11),15.1-15.5.

7. JongBoonOoi, Xin Wang, ChingSeong Tan, Jee-HouHo, Ying Pio Lim. Modal and stress analysis of gear trains design in portal axle using finite element modelling and simulation. Journal of Mechanical Science and Technology, 2012;26 (2): 575589.

8. Carbonscout/CG TEC GmbH GewerbeparkHugelmuhle 4191174 Spalt ,Germany.https://www.carbonscout-shop.de/HomeContact.html

9. SiemensAktiengesellschaft Werner-von $\quad$ Siemens-straße1 $80333 \quad$ Munich Germany,https://community.sw.siemens.com/s/article/getting-started-with-modal-curvefitting.

10. Jimin He, Zhi-Fang Fu.Modal Analysis .First Published.

11. Oxford: Butterworth-Heinemann; 2001.

12. ANSYS Composite PrepPost Users Guide, Release 15.0, November 2013.

13. Moro Oliver Boffoue, BrahimanTraore, ConandHonoreKouakou, Kokou Esso Atcholi, Remy Lachat.Experimental Determination of the Poisson's Ratio and the Elastic Modulus of a Sand-Plastic Composite Material. International Journal of Engineering Research, 2017;6(6):292-297.

14. SvendGade, Henrik Herlufsen. Digital Filter Techniques vs. FFT Techniques for Damping Measurements.Technicalreview . No.1:Brüel\&Kjar, 1994.

15. Z. Zeng, J. Li, S. Zhang, Y. Hong, et Y. Wang .Analysis of the Harmonic Response of a Modulation Permanent Magnetic Transmission Equipment Based on ANSYS.Energy and Power Engineering. 2015;7:63-70.

16. Paper: M. Sofian D. Hazry K. Saifullah M. TasyrifK.SallehI.Ishak. A study of Vibration Analysis for Gearbox Casing Using Finite Element Analysis . Proceedings of International Conference on Applications and Design in Mechanical Engineering (ICADME), 11 - 13 October 2009, BatuFerringhi, Penang, MALAYSIA.

17. Thomas .Calculus.1 $1^{\text {th }}$ Edition : Addison-Wesley, 2005, pp-12. 

